\title{
SOUND EFFECT ON DYNAMICS AND STABILITY OF FLUID SLOSHING IN ZERO-GRAVITY
}

\author{
I. A. L U K O V S K Y, A. N. T IMOK H A \\ Institute of Mathematics of NAS of Ukraine, Kyiv \\ Received 12.05.99 $\diamond$ Revised 17.08.99
}

\begin{abstract}
Theoretical study of acoustic interaction affecting the dynamics and stability of limited fluid volume in zero-gravity is carried out. Two main acoustic effects on a fluid surface are analyzed. The first is the change of dynamic characteristics of fluid sloshing in zero-gravity due to acoustic loading; the second is the movement of a "fluid cork" along the tube (acoustic pumping). Mathematical analysis is based on the averaging of original free interface problem. This allows to reduce a free interface problem to a free boundary problem on surface waves with additional nonlinear terms in the dynamic condition on an unknown surface. Nonlinear phenomena are described per structuring a series of analytical and numerical-analytical solutions. These examples concern the cylindrical vessel with gravity vector along the directrix and, hence, comparison of the results with solutions of capillary problem becomes available. The experimental conclusion that acoustic loads can give rise to equilibrium shapes contrasting to capillary surfaces is confirmed. Also the phenomena of acoustic stabilization and destabilization of "fluid-gas" interface are demonstrated including the case when such a destabilization causes the acoustic pumping.
\end{abstract}

Проведено теоретическое исследование акустического вэаимодействия, определяющего динамику и устойчивость ограниченного объема жидкости в невесомости. Проаналивированы два основных типа воздействия акустического поля на свободную границу. Первый состоит в иэменении динамических характеристик плесканий жидкости в невесомости под воздействием акустического нагружения. Второй ассоциируется в технических приложениях с движением "жидкой пробки" вдоль трубы (акустический насос). Математический анализ базируется на усреднении исходной задачи со свободной границей раздела двух сред, что позволяет свести задачу к задаче со свободной границей о поверхностных волнах $с$ дополнительными членами в динамическом условии на неиэвестной свободной поверхности. Нелинейные эффекты описываются путем построения ряда аналитических и численно-аналитических решений этой вадачи. Примеры относятся к случаю цилиндрического сосуда, когда вектор гравитации направлен вдоль оси цилиндра, что повволяет сравнить их с решениями вадачи о капилляре. Теоретические исследования подтверждают выводы, полученные в экспериментах, о том, что акустическое вовдействие может приводить к положениям равновесия на границе равдела, которые отличаются от капиллярных поверхностей. Кроме того, продемонстрованы эффекты динамической акустической стабиливации и дестабилизации поверхности раздела, включая случай, когда дестабиливация обуславливает өффект акустического насоса.

Проведено теоретичне дослідження акустичної вэаємодії, яка виэначає динаміку та стійкість обмеженого об'єму рідини у невагомості. Проаналівовано два основних типи впливу акустичного поля на вільну границю. Перший полягає у вміні динамічних характеристик плескань рідини у невагомості під впливом акустичного навантаження. Другий асоціюеться у технічних застосуваннях з рухом "рідкої пробки" вздовж труби (акустичний насос). Математичний аналіэ бавується на осередненні вихідної вадачі в вільною границею равділу двох середовиш, шо довволяє звести задачу до задачі з вільною границею про поверхневі хвилі з додатковими членами у динамічній умові на невідомій вільній поверхні. Нелінійні ефекти описуються черев побудову ряду аналітичних і чисельно-аналітичних ровв'язків цієї вадачі. Приклади наведено для випадку циліндричної посудини, коли вектор гравітації направлений вэдовж вісі циліндра, що доэволяє порівняти їх в роэв'яэками эадачі про капіляр. Теоретичні дослідження підтверджують висновки, одержані у експериментах, про те, шо акустичний вплив може привводити до положень рівноваги на границі розділу, які відрізняються від капілярних поверхонь. Окрім того, продемонстровані ефекти динамічної акустичної стабілівації та дестабілівації поверхні ровділу, включаючи випадок коли дестабілівація обумовлює ефект акустичного насоса.

\section{NOMENCLATURE}

- $Q(W(x, y, z) \leq 0)$ is the interior of a tank;

- $Q_{2}(t)$ is fluid subdomain in $Q$;

- $Q_{1}(t)$ and $Q_{3}(t)$ are gas subdomains;

- $\Sigma(t): \xi(x, y, z, t)=0$ (or $\Sigma_{1}(t), \Sigma_{2}(t)$ for the third problem) are "fluid-gas" interfaces;

- $\langle\Sigma\rangle(\tau)(\zeta(x, y, z, \tau)=0), \quad \Sigma_{i}(\tau)\left(x=H_{i}(y, z, \tau)\right)$, $i=1,2$, are averaged interfaces describing the slow-time interface fluctuations;

- $\Sigma_{0}\left(\zeta_{0}(x, y, z)=0, x=H_{0}(y, z)\right) \quad\left(\right.$ or $\quad \Sigma_{0 i}(x=$ $\left.\left.=H_{0 i}(y, z)\right), i=1,2\right)$ is capillary-acoustic equi- librium shape (averaged in time profile of interface);

- $S_{1}\left(S_{3}\right)$ is tank's wall touching the gas;

- $S_{2}$ is tank's wall touching the fluid;

- $S_{0} \subset S_{1}$ is a sound vibrator;

- $\varphi_{i}(x, y, z, t), i=1,2$, are the velocity potentials of gas and fluid;

- $l$ is size of the tank;

- $\rho_{i}(x, y, z, t), i=1,2$, are densities of gas and fluid;

- $p_{i}(x, y, z, t), i=1,2$, is pressure; 
- $\nu$ is frequency of acoustic excitation;

- $\boldsymbol{n}$ is the outer normal to $Q$ (or outer normal to $Q_{2}$ on the interface $\Sigma$ );

- $\sigma$ is the coefficient of surface tension;

- $g$ is virtual gravity acceleration;

- $\gamma_{i}, i=1,2$, are Theta's constants;

- $\rho_{0 i}, i=1,2$, are averaged densities;

- $\partial \Sigma$ is "fluid-gas-tank" contact line;

- $\alpha$ is "fluid-gas-tank" contact angle;

- $\mathcal{K}_{1}+\mathcal{K}_{2}$ is mean curvature;

- $p_{01}$ is "atmospheric" pressure;

- $c$ is the sound speed in gas;

- $\mathrm{Bo}=g l^{2} \rho_{02} / \sigma$ is Bond number;

- $k=\nu l / c$ is wave number of acoustic field;

- The expression $F x$ means a derivative of function $F$ by variable $x$.

\section{INTRODUCTION}

A limited fluid volume occupying halfly a tank of some vehicle (missile, marine tanker, petroleum cistern etc.) or orbiting satellite (e. g., spacelab or shuttle) performs a complete wave motion associated with mobility of its free surface (sloshing). In ground conditions the sloshing is caused by dominating gravity and inertial forces. In zero-gravity these factors are sufficiently small to effect the sloshing. Then the surface tension is the only primary force returning the fluid volume in its unperturbed stationary capillary equilibrium position. The another short-life excitations having determinated or random nature never lead to stabilization of capillary shape. Typically, they form the accident waves and destroy continuity of the media. There exist two engineering problems involving fluid sloshing in zero-gravity that motivate the study of behavior of a fluid volume in an orbiting vehicle. The first is the problem of keeping of fluids in prescribed subdomain of a vessel (positioning). The second is creation of driving forces to achieve pumping between the tanks (pumping). The usual way to overcome these technical problems is based on use of either active methods (acceleration of vehicle, electromagnetic fields, ejecting membranes etc.) or passive devices suppressing the fluid (partitions, obstacles, membranes, etc.). Both methods require the additional constructions and devices with rather massive components.

A number of experimental studies, in which the effect of high-frequency periodic loading on fluid sloshing is examined, allows one to suggest the use of vibrations as an efficient approach for actuation of the fluid and solving the management problems. The effect of sound (or vibration) on a limited fluid volume in microgravity can change the dynamic features of free surface [1-8]. Devices producing the acoustic or vibrational fields are not massive and do not require the considerable energy expenditure. In addition, if the acoustic field produces an effective pressure (acoustic radiation) positioning the fluid in container then the dynamics of container (and, of course, the vehicle motions) does not undergo a change $[1,8,9]$, therefore no orbit correction is required. However, implementation of acoustic methods is questionable without detailed preliminary theoretical investigation of the problem. The reason for this state of art is the rise of paradoxical phenomena in behavior of the sloshing in tank under vibroloading. The papers below report the distortion of capillary forms visualized as craters or fountains on a free surface $[2,3,5,6]$, stabilization and destabilization of th efree surface attended by active evaporation from "fluid-gas" interface (for cryogenic case) $[1,4-6,9,10]$, deformation, levitation, rotation and the destroying of fluid drops in standing acoustic field $[7,8,10]$ etc.

In this paper we develop an analytical approach based on the methods of theory of sloshing in microgravity. It allows us to examine some of the mentioned phenomena. Originating from the original hydrodynamic problem on coupled flows of two compressible media we apply an asymptotic method and averaging technique to derive a new free boundary problem (asymptotic model) describing the slow-time interface vibration. The analysis of analytical and numerical-analytical solutions of this free boundary problem gives the explanation of nature of a number of nonlinear vibroacoustic phenomena.

\section{ACOUSTIC RAdiation PRESSURE AS A GOVERNING FORCE}

In fig. 1 the three typical situations involving the sound loading for control of a fluid volume in microgravity are presented. They are associated with levitating, destroying or assembling drops, stabilization of shape of fluid domain and pumping of bounded fluid volume ("sliding fluid cork") along a tube. On contrary to vibrations of the vehicle, this "vibromethod" does not involve the vessel in a coupled pulsation. Local pulsations of vibrating subarea on 


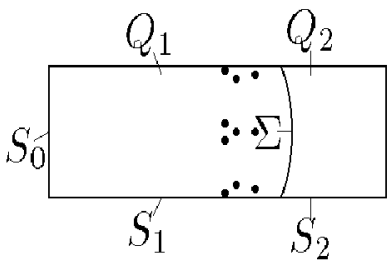

a

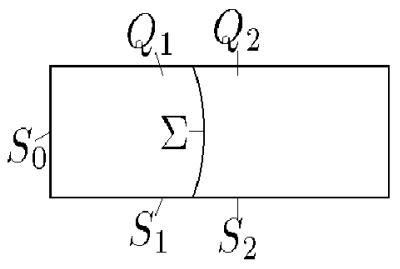

$b$

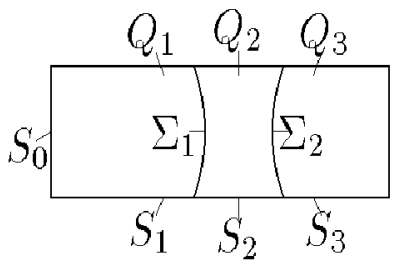

$c$

Fig. 1. Three implementations of sound control method in zero-gravity conditions: $a$ - assembling fluid drops; $b$-positioning a fluid domain; $c$-pumping a "fluid cork"

$S_{1}$ are transmitted by standing acoustic wave in $Q_{1}$ upon the "fluid-gas" interface. This standing wave fluctuates slowly in time-varied gas domain $Q_{1}(t)$ driven by the slow-time sloshing of reflecting surface (interface) $\Sigma(t)$. In addition, standing acoustic field yields in $Q_{1}$ a "radiant" energy implying itself a stationary (in sense of averaged pulsations) acoustic radiation pressure as well as acoustic vibration. This means, that the pressure distribution upon $\Sigma(t)$ has both quick-time (pulsation) and slow-time (averaged acoustic radiation pressure fluctuations) components. The pressure distribution determines the sloshing of the reflecting interface. The above speculations explain the reasons of studying of mutual "interfaceacoustic radiation pressure" influence.

Influence of the acoustic radiation pressure on the surface waves is low-investigated in experiments. The most of works study a special class of ultrasonic phenomena associated with either ultrasonic capillary effect (fluid flow in thin narrow flexible tube caused by progressive elastic waves along it) or acoustically driven jet emergency from the free surface when local ultrasonic vibrator is situated near the bottom. Moreover, only few papers examine the effect of standing acoustic field onto "fluid-gas" interface. Just these investigations concern the subject of our research.

We should distinguish two different situations of "standing acoustic wave-interface" interaction. The both should be referred to pure microgravity hydromechanics. The first one appears when the acoustic wavelength is longer then characteristic spatial size of interface. For the another situation the wavelength and the interface length are comparable. Acoustically levitated large drops and acoustically forced interface sloshing are two typical examples of this last situation. One is evident, that the key problem in the analysis of these microgravity phenomena is the question of stability of the interface due to acoustic load.

Preliminary analysis in the experimental works $[1,3,7,11,12]$ uses either phenomenological or energetic approaches to predict the interface instability. Estimation of the acoustic radiation energy affecting the evaporation allows to explain qualitatively the fluid pumping when the exciting frequency is situated in the neighborhood of the first acoustic natural tone in gas. However, these approaches are not able to describe the interface profile and calculate the frequency range where instability of the interface occurs.

The another approach is to consider a lumped energy amount (surface tension, gravity plus the energy of acoustic radiation pressure) to derive a minima principle for "potential energy". Mentioned approach was proposed for some classes of the surface wave problems in [13]. Such phenomenological method in [11] was used to analyze the stability of levitated fluid drops in crossed standing acoustic waves due to a chosen fluctuation of drop's shape. In discussed paper the one-parametric family of fluctuations was chosen and the problem was reduced to minima problem for a function of one variable.)

We consider the problem on "gas-fluid" interface sloshing exposed to acoustical excitation by vibrator situated in gas domain. When launching from model disposition of continuum media in accordance to scheme shown in fig. $1, b$ we implement an averaging technique coupled with methods developed for classical capillary sloshing problem [14-16]. This approach allows us to overcome the principal theoretical difficulties and apply well-known spectral approach used to analyze the stability of capillary equilibria [16]. We get the problem on capillary-acoustic equilibria (profile of the interface is determined by a balance of surface tension, gravitation, and acoustic radiation pressure). This equilibrium interface can be treated as an averaged in time interface's shape if steady-state motion of "fluid-gas" system occurs. The capillary-acoustic equilibrium shape differs from capillary one. In this paper we show that the relative slow-time sloshing with respect to 
this equilibrium surface is also different from capillary waves in tank and have drastically different hydrodynamic characteristics of these "acoustic" sloshing (natural frequencies, natural modes, stability response due to diverse excitations etc.).

The last experimental investigations of levitation of the drops in standing acoustic waves conducted in spacelab USML-2 $[9,11]$ confirmed the strong dependence of stability of the drop on acoustic radiation. The analysis of this phenomenon being done in $[7,8,10,11]$ is based on theoretical estimation of distribution of the acoustic radiation pressure across the drop's surface. Such approach proposed earlier in [13] introduces the additional nonlinear terms corresponding to acoustic radiation pressure in governing equations. Mentioned terms can be treated as the averaging vibroforces first proposed by P. Kapitsa [17] for analysis of vibrostabilization of vertical pendulum (see also [18]). The experimental results obtained for rigid body dynamics are in good agreement with vibrophenomena occurring in hydrodynamic systems $[4-6]$. This means that we can extent some results of rigid body vibromechanics onto the examined case accounting only the basic balancing forces, namely, the surface tension, gravitation and the acoustic radiation pressure. Also, it should be noted that the model of perfect compressible fluid and gas is applicable to describe the basic nonlinear phenomena known from experiments. Hereinafter we consider the potential flows.

Note, that similar assumption (inviscid potential flows, gravity field and surface tension) forms the base of classical free boundary problem on sloshing of incompressible fluid in vessels (capillary - gravity waves):

$$
\begin{aligned}
& \Delta \varphi=0 \text { in } Q(t), \\
& \frac{\partial \varphi}{\partial n}=0 \text { on } S(t), \\
& \int_{Q(t)} d Q=\text { const, } \\
& \frac{\partial \varphi}{\partial n}=-\frac{\xi, t}{|\nabla \xi|} \text { on } \Sigma(t), \\
& \frac{\partial \varphi}{\partial t}+\frac{1}{2}(\nabla \varphi)^{2}+\mathcal{A} \xi=0 \text { on } \Sigma(t),
\end{aligned}
$$

where the interface is $\Sigma(t): \xi(x, y, z, t)=0$. The velocity potential $\varphi(x, y, z, t)$ in general should be determined; $\mathcal{A}$ is the operator of potential forces (gravity, surface tension etc.). This problem (1) differs from the problem below so long as it neglects the compressibility.

Some aspects of theory of sloshing were developed in $[15,16,19]$. This theory used to be implemented into industry problems associated with coupled "body-fluid" motions and calculation of the dynamics of capillary fluid in spacecraft vehicles. The problem on capillary equilibrium shape follows immediately from (1) if $\varphi$ and $\xi$ are not dependent on $t$. We refer the readers who interest in the results of corresponding theory to the transactions $[16,19-23]$.

In order to investigate the sloshing exposed to highfrequency excitation we should take into account the compressibility. Preprint [24] presents the elements of such theory for mathematical problems modeling the "vibro-sloshing". Krylov-Bogolyubov-Mitropolskii averaging technique is used in developed theory. In the present paper we follow the same way to analyze a coupled "gas-fluid" sloshing noted in fig. 1 as problems $b$ and $c$. The main governing free boundary problem derived from the original hydrodynamic problem contains the nonlinear terms coinciding with the expression for Langevin acoustic radiation pressure. These terms appear in dynamic condition on "fluid-gas" interface.

\section{PROBLEM ON SLOSHING OF COMPRESS- IBLE MEDIA DUE TO ACOUSTIC EXCITA- TION. ASYMPTOTIC (AVERAGED) PROB- LEM}

We examine wave motions of "fluid $Q_{2}(t)-$ gas $Q_{1}(t)$ " interface $\Sigma(t)$. The gas and the fluid are suggested to be compressible. The sound vibrator is situated on part of the wall $S_{0}$ in way to be always touching only gas domain $Q_{1}$. It produces an acoustic field in the gas. Note, that for all numerical examples we consider the following parameters: frequency range of acoustic field $1 \div 3 \mathrm{kHz}$, Bond numbers $0 \div 30$ for the characteristic size of the tank $0.05 \div 1 \mathrm{~m}$.

\subsection{Statement of the problem}

Governing equations in the both continuum media $(i=1,2)$ are the following:

$$
\begin{gathered}
\frac{\partial \rho_{i}}{\partial t}+\operatorname{div}\left(\rho_{i} \nabla \varphi_{i}\right)=0 \\
\rho_{i} \nabla\left(\frac{\partial \varphi_{i}}{\partial t}+\frac{1}{2}\left(\nabla \varphi_{i}\right)^{2}+g x\right)=-\nabla p_{i} \\
\rho_{i}=\rho_{0 i}\left(\frac{p_{i}}{p_{0 i}}\right)^{1 / \gamma_{i}} \text { in } Q_{i}(t) .
\end{gathered}
$$

Zero Neumann (no-slip) condition is fulfilled on the wall of the tank $Q$ :

$$
\frac{\partial \varphi_{i}}{\partial n}=0 \text { on } S_{i}
$$


kinematic and dynamic boundary conditions should be satisfied on interface:

$$
\begin{gathered}
\frac{\partial \varphi_{i}}{\partial n}=-\frac{\xi_{, t}}{|\nabla \xi|} \text { on } \Sigma(t), \quad i=1,2, \\
-p_{1}=-p_{2}+\sigma\left(\mathcal{K}_{1}+\mathcal{K}_{2}\right) \text { on } \Sigma(t)
\end{gathered}
$$

along with the condition on contact line:

$$
-\frac{(\nabla W, \nabla \xi)}{|\nabla W|}=\cos \alpha|\nabla \xi| \text { on } \partial \Sigma(t) .
$$

The distribution of normal velocity $V_{0}(x, y, z) \sin (\nu t)$ on the vibrator

$$
\rho_{1} \frac{\partial \varphi_{1}}{\partial n}=\rho_{01} V_{0}(x, y, z) \sin (\nu t) \text { on } S_{0}
$$

completes this interface value problem.

The solution of $(2)-(6)$ is the set of functions $\varphi_{i}(x, y, z, t), p_{i}(x, y, z, t), \rho_{i}(x, y, z, t)$ and $\xi(x, y, z, t)$.

Let $l$ be a characteristic size of $Q$ and $t_{*}=1 / \nu$ be a characteristic time. Then the dimensionless problem takes the following form:

$$
\begin{aligned}
& \frac{\partial \rho_{i}}{\partial t}+\operatorname{div}\left(\rho_{i} \nabla \varphi_{i}\right)=0, \\
& \rho_{i} \nabla\left(\frac{\partial \varphi_{i}}{\partial t}+\frac{1}{2}\left(\nabla \varphi_{i}\right)^{2}+\operatorname{Bo} x \nu_{*}^{-2}\right)=-\nabla p_{i}, \\
& \rho_{i}=\left(\frac{p_{i}}{p_{0 i}}\right)^{1 / \gamma_{i}} \text { in } Q_{i}(t), \\
& \frac{\partial \varphi_{i}}{\partial n}=0 \text { on } S_{i}, \\
& \frac{\partial \varphi_{i}}{\partial n}=-\frac{\xi_{, t}}{|\nabla \xi|}, \text { on } \Sigma(t), \\
& -p_{1} \frac{\rho_{01}}{\rho_{02}}=-p_{2}+\nu_{*}^{-2}\left(\mathcal{K}_{1}+\mathcal{K}_{2}\right), \text { on } \Sigma(t), \\
& \rho_{1} \frac{\partial \varphi_{1}}{\partial n}=\frac{\sup \left|V_{0}(x, y, z)\right|}{c \mu_{0}} \times \\
& \quad \times \frac{\mu_{0}}{k} V(x, y, z) \sin t \text { on } S_{0}, \\
& -\frac{(\nabla W, \nabla \xi)}{|\nabla W||\nabla \xi|}=\cos \alpha \text { on } \partial \Sigma(t),
\end{aligned}
$$

where

$$
\begin{gathered}
V(x, y, z)=V_{0}(x, y, z) / \sup \left|V_{0}\right| \\
\nu_{*}^{2}=\nu^{2} l^{3} \rho_{02} / \sigma .
\end{gathered}
$$

\subsection{Asymptotic analysis}

The dimensionless problem (7) has several small parameters. One of them $\varepsilon=\sup \left|V_{0}\right| /\left(c \mu_{0}\right) \ll 1$ expresses the smallness of amplitude of vibrations in gas domain with respect to sound speed $M=\sup \left|V_{0}\right| / c$ what is typically correct in acoustic approximation of compressible flow. Value of $\mu_{0}$ is actually the relation between $M$ and $\varepsilon$ :

$$
\mu_{0}=\frac{M}{\varepsilon}, \quad\left|\mu_{0}\right| \sim 1 .
$$

The Bond number Bo implies the relation between gravitation and surface tension.

We assume, that other small parameters depend on $\varepsilon$ according to the following relations:

$$
\begin{aligned}
\frac{\rho_{01}}{\rho_{02}}=\mu_{1} \varepsilon, & \left|\mu_{1}\right| \sim 1, \\
\nu_{*}^{-2}=\mu \mu_{1} \varepsilon^{3}, & |\mu| \sim 1 .
\end{aligned}
$$

The first relation implies the smallness of gas density with respect to fluid density. This means, that the second order component of pressure in $Q_{1}$ yields the third order terms on interface when interaction between the subdomains occurs. The dimensionless parameter $\nu_{*}^{-2}$ is sufficiently small for large $\nu$. If $V_{0}=0$ the original problem is reduced to the problem on free coupled vibrations of compressible fluid and gas in a tank. Natural (eigen) vibration of such system were investigated in [25]. The analysis of corresponding spectral problem has shown that each natural mode of the interface has an infinite set of eigenvalues. The lowest elements of these sets complete a subsequence of eigenvalues (sub-spectrum). This sub-spectrum corresponds to natural motions of the system due to mobility of the interface; it is close to spectrum of the problem on capillary natural vibration of incompressible fluid. Other eigenvalues correspond to vibration of the system due to compressibility. They are sufficiently large-scaled ones.

If $t_{*}=\nu^{-1} \ll 1$ is sufficiently small and wave number $k \sim 1$ ( $\nu$ is situated in the vicinity of dominating natural tone of acoustic pulsation in gas), then value of the lowest ("sloshing" spectral component mentioned above) is ordered as $\sqrt{\nu_{*}^{-2}}$ (both the surface tension and gravitation have order $\nu_{*}^{-2}$ in the $\mathrm{dy}-$ namic conditions). The acoustic radiation pressure has asymptotic order $\varepsilon^{2} \rho_{01} / \rho_{02}=\mu_{1} \varepsilon^{3}$ in the dynamic condition. To provide the similar order between these three interacting forces we should suggest $\nu_{*}^{-2} \sim \mu_{1} \varepsilon^{3}$ or suppose the second relation from (8) to be fulfilled. That is why $\mu$ implies the relation between potential forces (surface tension, gravitation and acoustic radiation pressure):

$$
\mu=\frac{\sigma l^{-3}}{\nu^{2} \varepsilon^{2} \rho_{01}}=\frac{1}{\nu_{*}^{2} \varepsilon^{2} \rho_{01} \rho_{02}^{-1}} .
$$

We can use asymptotic technique and the method of separation of quick-time (pulsation) and slow-time 
components to derive an averaged asymptotic problem describing the slow-time interface sloshing.

\subsection{Asymptotic averaged problem}

When introducing the quick-time $t$ and the slowtime $\tau=\varepsilon^{3 / 2} t$ we assume the functions $\varphi_{i}, p_{i}$ and $\xi$ to be depending on $x, y, z, t$ and $\tau$. Then the solution of $(7)$ can be extended into series

$$
\begin{aligned}
& \varphi_{i}=\sum_{k} \varepsilon^{k / 2} \varphi_{i}^{(k / 2)}(x, y, z, t, \tau), \\
& p_{i}=\sum_{k} \varepsilon^{k / 2} p_{i}^{(k / 2)}(x, y, z, t, \tau), \\
& \xi=\sum_{k} \varepsilon^{k / 2} \xi_{(k / 2)}(x, y, z, t, \tau) .
\end{aligned}
$$

When setting (9) into (7) (with taking into account (8)) we reduce the solving of the original problem to a sequence of the problems with respect to $\varphi_{i}^{(k / 2)}, p_{i}^{(k / 2)}, \xi_{(k / 2)} ; i=1,2, k=0,1,2, \ldots$ The lowest order asymptotic solution depends on zero-, first-, second- and third-order approximations. The another approximations can be found recursively from the above ones. The averaging procedure selects out two independent functions determining the slow-time interface sloshing:

$$
\begin{aligned}
& \Phi_{2}(x, y, z, \tau)=\left\langle\varphi_{2}\right\rangle_{, t}= \\
& \quad=\varepsilon^{3 / 2} \varphi_{2}^{(3 / 2)}\left(x, y, z, \varepsilon^{3 / 2} t\right)+o\left(\varepsilon^{3 / 2}\right),
\end{aligned}
$$

and

$$
\zeta(x, y, z, \tau)=\langle\xi\rangle, t=\xi_{0}(x, y, z, \tau)+o\left(\varepsilon^{2}\right) .
$$

Finally, we introduce

$$
\Phi_{1}(x, y, z, \tau)=\varphi_{1}^{(1)}(x, y, z, \tau, t) / \sin t
$$

(here $\Phi_{1}$ is wave function of the acoustic field in gas) describing the slow-time fluctuation of the acoustic field in $Q_{1}$.

The asymptotic procedure transforms the original free interface problem to nonlinear approximate (asymptotic) boundary value problem:

$$
\begin{aligned}
& \Delta \Phi_{2}=0 \text { in }\left\langle Q_{2}\right\rangle(\tau), \\
& \frac{\partial \Phi_{2}}{\partial n}=0 \text { on }\left\langle S_{i}\right\rangle, \\
& \frac{\partial \Phi_{2}}{\partial n}=0 \text { on }\left\langle S_{2}\right\rangle \text {, } \\
& \frac{\partial \Phi_{2}}{\partial n}=-\frac{\zeta_{, \tau}}{|\nabla \xi|} \text { on }\langle\Sigma\rangle(\tau), \\
& \Phi_{2 \tau}+\frac{1}{2}\left(\nabla \Phi_{2}\right)^{2}+\mu \mu_{1}\left(\text { Bo } x-\left(\mathcal{K}_{1}+\mathcal{K}_{2}\right)\right)+ \\
& +\frac{1}{4} \mu_{1}\left(k^{2}\left(\Phi_{1}\right)^{2}-\left(\nabla \Phi_{1}\right)^{2}\right)= \\
& =\operatorname{const}(\tau) \text { on }\langle\Sigma\rangle(\tau), \\
& -\frac{(\nabla W, \nabla \zeta)}{|\nabla W||\nabla \zeta|}=\cos \alpha \text { on } \partial\langle\Sigma\rangle(\tau), \\
& \int_{\left\langle Q_{2}\right\rangle} d Q=\text { const } \\
& \Delta \Phi_{1}+k^{2} \Phi_{1}=0 \text { in }\left\langle Q_{1}\right\rangle(\tau), \\
& \frac{\partial \Phi_{1}}{\partial n}=0 \text { on }\left\langle S_{1}\right\rangle \cup\langle\Sigma\rangle(\tau), \\
& \frac{\partial \Phi_{1}}{\partial n}=\mu_{0} \frac{V(x, y, z)}{k} \text { on } S_{0} .
\end{aligned}
$$

2.4. Asymptotic approximate problem as a sloshing problem

The problem (10), (11) is an analogy of the problem on sloshing (1). The dynamic condition in the boundary problem (10) includes the nonlinear operator $\mathcal{A}$ corresponding to a "potential force"

$$
\mathcal{A} \zeta=\mu \mu_{1}\left(\operatorname{Bo} x-\left(\mathcal{K}_{1}+\mathcal{K}_{2}\right)\right)+
$$

$$
+\frac{1}{4} \mu_{1}\left(k^{2}\left(\Phi_{1}\right)^{2}-\left(\nabla \Phi_{1}\right)^{2}\right) \text { on }\langle\Sigma\rangle(\tau),
$$

where $\Phi_{1}(x, y, z, \tau)$ is the solution of system (11). Above $\Phi_{2}$ depends on $\Phi_{1}$ and $\Phi_{1}$ depends parametrically on the profile of sub-boundary $\langle\Sigma\rangle(\tau)$ so long as it satisfies Neumann boundary problem (11) with varied $\langle\Sigma\rangle(\tau)$.

To compare this problem with well-investigated problem on capillary-gravity waves we should set $V(x, y, z) \equiv 0$. Then $\Phi_{1}(x, y, z)=$ const and the derived problem is immediately transformed to problem on capillary waves in a tank $Q[16,24]$.

The theory of capillary waves in tank consists of the theory of capillary equilibria and the theory of relative capillary waves $[16,19-23]$. If relative capillary 
waves are sufficiently small, the problem is rewritten to the spectral problem with spectral parameter on unperturbed free surface $[16,19]$. The solutions of this problem describe the natural vibration. When analyzing the signs of the eigenvalues for various physical parameters we make the conclusions on the stability of capillary equilibrium shape.

Below we place our emphasis on case of non-zero function $V(x, y, z)$.

\section{CAPILLARY - ACOUSTIC EQUILIBRIA}

The problem on equilibria for given case can be obtained under the assumption that we have no slowtime waves on the interface $(\xi=\xi(x, y, z))$.

If the free surface $\langle\Sigma\rangle(\tau)$ does not evolute in time $\tau$ then $\Phi_{2}=$ const, $\Phi_{1}=\Phi_{01}(x, y, z), \quad \zeta=\zeta_{0}(x, y, z)$. The problem (10), (11) is reduced to a stationary free boundary problem in averaged domain $Q_{0} \stackrel{d f}{=}\left\langle Q_{1}\right\rangle$ with unknown free boundary $\Sigma_{0} \stackrel{d f}{=}\langle\Sigma\rangle$ :

$$
\begin{gathered}
\mu\left(\operatorname{Bo} x-\left(\mathcal{K}_{1}+\mathcal{K}_{2}\right)\right)+ \\
+\frac{1}{4}\left(k^{2}\left(\Phi_{01}\right)^{2}-\left(\nabla \Phi_{01}\right)^{2}\right)=\text { const on } \Sigma_{0}, \\
-\frac{\left(\nabla W, \nabla \zeta_{0}\right)}{|\nabla W|}=\cos \alpha\left|\nabla \zeta_{0}\right| \text { on } \partial \Sigma_{0}, \\
\int_{\left\langle Q_{2}\right\rangle} d Q=\text { const, } \\
\Delta \Phi_{01}+k^{2} \Phi_{01}=0 \text { in } Q_{0}, \\
\frac{\partial \Phi_{01}}{\partial n}=0 \text { on }\left\langle S_{1}\right\rangle \cup \Sigma_{0}, \\
\frac{\partial \Phi_{01}}{\partial n}=\mu_{0} \frac{V(x, y, z)}{k} \text { on } S_{0} .
\end{gathered}
$$

Here $\Sigma_{0}\left(\zeta_{0}(x, y, z)=0\right)$ is the averaged shape of $\Sigma(t)$. It was named as the capillary-acoustic equilibrium (CAE) shape. The problem (12) implies the dependence between the shape of averaged surface (shape of fluid) and geometry of the acoustic field in gas. The first equation from (12) expresses the relation between surface tension, gravitation and the acoustic radiation pressure when interacting with each other.

The solution of the problem (12), (13) consists of two functions: $\zeta_{0}$ and $\Phi_{01}$. The first function describes the averaged interface $\Sigma_{0}$, while the second one should be found from the inhomogeneous Neumann boundary value problem (for this last problem a part of boundary coincides with $\Sigma_{0}$ ). Moreover, governing equation on $\Sigma_{0}$ includes the nonlin- ear terms depending on $\Phi_{01}$. Thus, wave function $\Phi_{01}$ effects the capillary - acoustic equilibrium shape $\Sigma_{0}$ and the profile of this equilibrium mode effects this wave function.

We can introduce the nonlinear operator $\mathcal{A}_{1}\left(\Sigma_{0}\right)$ and formally reduce the boundary value problem on capillary-acoustic equilibria to a class of capillary equilibrium problem with a special nonlinear operator corresponding to the acoustic pressure distribution on $\Sigma_{0}$ :

$$
\mathcal{A}_{1}\left(\Sigma_{0}\right)=\left.\frac{1}{2}\left(k^{2} \Phi_{01}^{2}-\left(\nabla \Phi_{01}\right)^{2}\right)\right|_{\Sigma_{0}}
$$

where $\Phi_{01}(x, y, z)$ is the solution of (13).

The boundary problem (12) can be interpreted as a capillary problem on equilibria augmented by the acoustic radiation pressure. This problem takes the form

$$
\begin{aligned}
& -\left(\mathcal{K}_{1}+\mathcal{K}_{2}\right)+\text { Bo } x+\frac{1}{\mu} \mathcal{A}_{\infty}\left(\Sigma_{0}\right)=\text { const, } \\
& -\frac{\left(\nabla W, \nabla \zeta_{0}\right)}{|\nabla W|\left|\nabla \zeta_{0}\right|}=\cos \alpha \text { on } \partial \Sigma_{0} \\
& \int_{\left\langle Q_{2}\right\rangle} d Q=\text { const. }
\end{aligned}
$$

Solvability of the nonlinear boundary problem (15) so far remains an open question even for a tank of simple shape. It is basically caused by difficulties arising in the analysis of main capillary term $-\left(\mathcal{K}_{1}+\mathcal{K}_{2}\right)$ present in governing equation. The solvability theorems on capillary equilibria were established only for cylindrical and conical tanks [16, 20, $21,26]$. The case of exotic tanks requires detailed analysis as well as the additional experimental investigations on orbiting station [20-23].

In this investigation we suppose that $Q$ has the cylindrical shape. This allows us to structure the analytical and numerical-analytical solutions, and compare the obtained data with known results of capillary theory.

\section{STABILITY OF CAE SHAPE}

We assume the interface $\langle\Sigma\rangle(\tau)$ to be initially perturbed with respect to $\mathrm{CAE}$. If this displacement is sufficiently small and the CAE is stable, the magnitude of the interface sloshing is also small. This means that we can consider the problem on linear vibration.

Let $Q$ has the cylindrical shape with vertical wall determined by equation $W(y, z)=0$ and bottoms $x=-h_{f} ; x=h_{g}$. Here $h_{f}$ is the height of fluid 
column; $h_{g}$ is the height of a gas (in unperturbed state). CAE surface can be described by equation $x=H_{0}(y, z)$ when the perturbed surface $\langle\Sigma\rangle(\tau)$ allows the explicit form $x=H(y, z, \tau)$. Linearized evolutional problem takes the form

$$
\begin{aligned}
& \Delta \phi_{2}=0 \text { in } Q_{0}, \\
& \frac{\partial \phi_{2}}{\partial n}=0 \text { on }\left\langle S_{2}\right\rangle, \\
& \left\{\begin{array}{l}
\frac{\partial \phi_{2}}{\partial n}=\frac{H_{\tau}}{\sqrt{1+\left(\nabla H_{0}\right)^{2}}}, \quad \text { on } \Sigma_{0}, \\
\phi_{2 \tau}+\mu \mu_{1} \mathcal{A} H=0
\end{array}\right.
\end{aligned}
$$

where

$$
\begin{aligned}
& \mathcal{A} H=-\operatorname{div}\left[\frac{\nabla H}{\sqrt{1+\left(\nabla H_{0}\right)^{2}}}-\right. \\
& \left.-\frac{\left(\nabla H, \nabla H_{0}\right) \nabla H_{0}}{\left(1+\left(\nabla H_{0}\right)^{2}\right)^{3 / 2}}\right]+ \\
& +\frac{2}{\mu}\left[k^{2} \Phi_{01} \Phi_{01, x} H-\left(\nabla \Phi_{01}, \nabla \Phi_{01, x}\right) H+\right. \\
& \left.+k^{2} \Phi_{01} \Phi-\left(\nabla \Phi_{01}, \nabla \Phi\right)\right]_{\Sigma_{0}}+ \\
& + \text { Bo } H \text { on } \Sigma_{0} \\
& \frac{\left(W_{, y} H_{, y}+W_{, z} H_{, z}\right)}{\left(W_{, y} H_{0, y}+W_{, z} H_{0, z}\right)}= \\
& =\frac{\left(\nabla H_{0}, \nabla H\right)}{\sqrt{1+\left(\nabla H_{0}\right)^{2}}} \text { on } \partial \Sigma_{0} \text {; } \\
& \int_{\Sigma_{0}} H d y d z=0 \\
& \Delta \Phi+k^{2} \Phi=0 \text { in } Q_{0} \\
& \frac{\partial \Phi}{\partial n}=0 \text { on }\left\langle S_{1}\right\rangle \cup S_{0} \\
& \frac{\partial \Phi}{\partial n}=\left[\Phi_{01, x x} H-\Phi_{01, z} H_{, z}-\Phi_{01, y} H_{, y}-\right. \\
& \left.-\left[\Phi_{01, x y} H_{0, y}+\Phi_{01, x z} H_{0, z}\right] H\right] \times \\
& \times 1 / \sqrt{1+\left(\nabla H_{0}\right)^{2}} \text { on } \Sigma_{0} \text {. }
\end{aligned}
$$

Here $\phi_{2}=\phi_{2}(x, y, z, \tau)$ determines the small motion of fluid; $\Phi(x, y, z, \tau)$ describes the small parametric evolution of wave function in $Q_{0}$ occurring due to the interface fluctuation $(x=H(y, z, \tau))$.

We introduce harmonic dependences of $\phi_{2}, H$ on $\tau: H(y, z, \tau)=\exp (i \lambda \tau) h(y, z)$ and $\phi_{2}(x, y, z, \tau)=$ $=i \lambda \exp (i \lambda t) \phi(x, y, z)[16]$. Natural modes $h, \phi$ and natural frequencies $\lambda$ can be found from the following spectral problem:

$$
\begin{aligned}
& \Delta \phi=0 \text { in } Q_{0}, \\
& \frac{\partial \phi}{\partial n}=0 \text { on }\left\langle S_{2}\right\rangle, \\
& \frac{\partial \phi}{\partial n}=\frac{h}{\sqrt{1+\left(\nabla H_{0}\right)^{2}}} \text { on } \Sigma_{0}, \\
& -\lambda^{2} \phi+\mu \mu_{1} \mathcal{A} h=0 \text { on } \Sigma_{0} .
\end{aligned}
$$

The problem (19) includes the squares of $\lambda$. This is the reason, why the sign of $\lambda^{2}$ subjects the stability of CAE. If the spectrum is strongly positive then CAE is stable. Else it is unstable in view of small initial perturbation. This allows to formulate the following "dynamic" spectral criterion of stability:

- CAE is stable if and only if $\lambda_{l}^{2}>0$ for all $l$.

The another way to analyze the stability of CAE is associated with studying the pressure balance fluctuation on interface $\Sigma_{0}$ due to its displacement. If the pressure balance is always distributed in such a manner that returning forces are directed to keep CAE shape, then $\Sigma_{0}$ is stable. Else $\Sigma_{0}$ is unstable. Since the pressure balance on CAE surface is given by governing equation (12) and operator $A$ corresponds to a perturbation of this balance for a small displacement $H$ the following "static" spectral criterion holds true: - $\eta>0$ for spectral problem $\mathcal{A} h=\eta h$.

Implementation of the spectral criteria is the efficient method to establish the stability properties for diverse capillary problems. In the next section we apply them to investigate CAE shapes for cases when the solution can be found in analytical form. In particular, spectral criteria of stability allow to establish that

1) planar CAE shape can demonstrate stability under negative over-critical gravitation (stabilization);

2) "fluid-gas" interface can demonstrate instability (resonance distortion) for positive Bond number when capillary surface is stable.

\section{STABILITY OF PLANAR CAE SHAPE}

The spectral problem on capillary sloshing in vertical circular cylinder allows the analytical solution for right contact angle $(\alpha=\pi / 2)$. It has been analyzed by many authors (see, for example, the monograph [16]). In this case capillary surface is planar and perpendicular to directrix of the cylinder. The 
spectral problem on natural sloshing can be solved by method of separation of spatial variables. This means, that $\zeta_{0}(x, r, \theta)=x-H_{0}(r, \theta)=0, H_{0}(r, \theta)=0$. Planar capillary surface is stable if and only if

$$
\text { Bo }>-\dddot{x}_{11} \text {, }
$$

where $J_{p}^{\prime}\left(æ_{p q}\right)=0 ; J_{p}(r)$ is Bessel function.

Natural frequencies $\tilde{\lambda}_{p q}$ of capillary waves can be found from spectral problem (19) (setting $\left.\Phi_{01} \equiv 0(V \equiv 0)\right)$, i.e.

$$
\begin{gathered}
\tilde{\lambda}_{p q}^{2}=\mu \mu_{1} æ_{p q} \text { th }\left(æ_{p q} h_{f}\right)\left(\mathrm{Bo}+æ_{p q}\right), \\
h_{p q}(r, \theta)=J_{p}\left(æ_{p q} r\right) \underset{\cos }{\sin }(p \theta) .
\end{gathered}
$$

Here we chose the values of characteristic dimension and characteristic time similar to that for CAE problem to make the comparison of capillary and capillary-acoustic problems easier.

Below we consider the problem on CAE for $\alpha=\pi / 2$. Depending on the shape of acoustic field modulated on $S_{0}$ this equilibrium interface state can be planar or non-planar one. The first (planar) case will be an object of our detailed analysis.

Under the above assumptions we suggest for a vertical circular cylindrical tank (in numerical examples it has radius $l=0.1 \mathrm{~m}$ ) to be partially filled by water and air at temperature $20^{\circ} \mathrm{C}$ and atmospheric pressure. The gravity is $10^{-5} \div 10^{-7} g_{0}$, the acoustic frequency is $700 \div 2000 \mathrm{~Hz}$.

\subsection{Non-planar capillary-acoustic equilibria}

The profile $\Sigma_{0}$ depends on not only contact angle, but also the distribution of normal velocity component on $S_{0}$. We show this via numerical examples calculated under the above assumptions.

If the acoustic field in gas over fluid is planar $\left(V_{0}(r, \theta)=v_{0}=\mathrm{const}, \varepsilon=-v_{0} / c \sin \left(k h_{g}\right), \mu_{0}=\right.$ $\left.=-\sin \left(k h_{g}\right), V(r, \theta)=1\right)$ then CAE shape is also planar and problem (12) has the analytical solution $H_{0}(r, \theta) \equiv 0$ ("trivial" solution) with wave function $\Phi_{01}(x, y, z)=k^{-2} \cos (k x)$. If the sound vibrator on $S_{0}$ modulates a non-planar acoustic field (and, therefore, the right hand side of boundary condition on $S_{0}$ is not constant), then CAE shape is not planar. We present some shapes of $\Sigma_{0}$ calculated when $V(r, \theta)=0.2+0.2 J_{0}\left(æ_{01} r\right)$ in fig. 2 .

\subsection{Planar capillary-acoustic equilibrium shape ( $V_{0}=$ const, $\alpha=\pi / 2$ )}

The case of planar CAE shape is convenient object to study the dependence of interface stability from acoustic loading. The case $V_{0}=$ const corresponds to a vibrating piston situated on the ceiling of the circular cylinder. For this case capillary and capillaryacoustic equilibrium shapes coincide with each other. We consider the natural vibration with respect to these "trivial" equilibrium profiles. Method of separation of spatial variables $x, r, \theta$ in cylindrical coordinate system gives the natural frequencies and natural modes in analytical form. One can show that natural modes $h_{p q}(21)$ are the same for the both cases. However, the natural frequencies differ from each other. The frequencies $\lambda_{p q}$ of capillary-acoustic waves are calculated as follows:

$$
\begin{gathered}
\lambda_{p q}^{2}=\mu_{1} æ_{p q} \text { th }\left(æ_{p q} h_{f}\right)\left[\mu\left(\mathrm{Bo}+æ_{p q}^{2}\right)-\right. \\
-\frac{1}{2}\left\{\begin{array}{cc}
1 /\left(\eta \operatorname{th}\left(\eta h_{g}\right)\right), & k^{2}<æ_{p q}^{2}, \\
-1 /\left(\eta \operatorname{tg}\left(\eta h_{g}\right)\right), & k^{2} \geq æ_{p q}^{2}
\end{array}\right], \\
\eta=\sqrt{\left|k^{2}-æ_{p q}^{2}\right|}
\end{gathered}
$$

The stability depends on the sign of $\lambda_{p q}^{2}$ and $\tilde{\lambda}_{p q}^{2}$. For capillary equilibria the squares of natural frequencies are positive if the condition (20) is satisfied. CAE is stable if the inequality $\lambda_{p q}^{2}>0$ for all $p q$ holds true.

We depict the stability response of planar CAE shape on wave number in fig. 3 ( $\mathrm{Bo}=10, \varepsilon=0.007$, $h_{g}=2$ ). Because of the positiveness of Bond number the planar capillary equilibrium shape is always stable. Obviously, planar CAE shape must be stable for $k$ lower then critical value. This value depends on type of perturbation. We interchange the perturbations in accordance with the sequence of natural modes $h_{p q}$. The ranges of stability for such perturbations are figured on axes $p q$. Note, that each axis $p q$ includes the range $\left(O_{p q}, O_{p q}^{\prime}\right)$. Here the point $O_{p q}$ coincides with the origin of axis $p q$ (it corresponds to $k=0$ ). This range is caused by positiveness of Bo and the point that CAE tends to capillary equilibria when $k \rightarrow 0, \mu(k) \rightarrow \infty$. We assume that $k \sim 1$. This one requires a speculative choice of $k_{1}$ on axis $O k$ to exclude small $k$ from consideration. Minimal range $\left(O_{11}, O_{11}^{\prime}\right)$ appears for $h_{11}$. It defines the critical value $k_{2}$ on $O k$ and the first range of stability $I=\left(k_{1}, k_{2}\right)$. When $k$ increases the ranges of stability and instability alternate each other.

Conclusion 1. If planar capillary interface is stable then planar CAE shape is stable for sufficiently small $k \in\left(k_{1}, k_{2}\right)$. The stability loss occurs for $k$ situated in right hand to $O_{11}^{\prime}$. The first instability range $\left(k_{2}, æ_{11}\right)$ is caused by the first acoustic resonance ( $æ_{11}$ is the first natural frequency). Hence, the instability phenomenon has resonance character. 


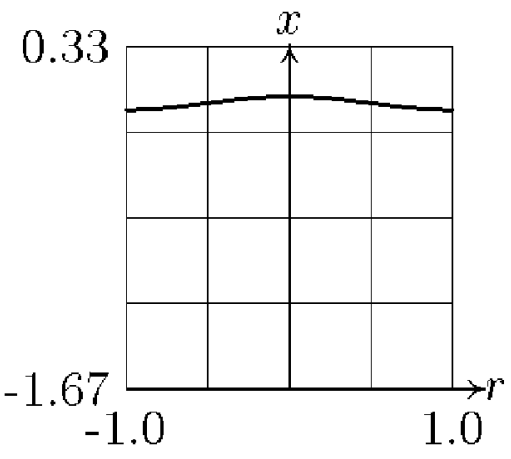

a

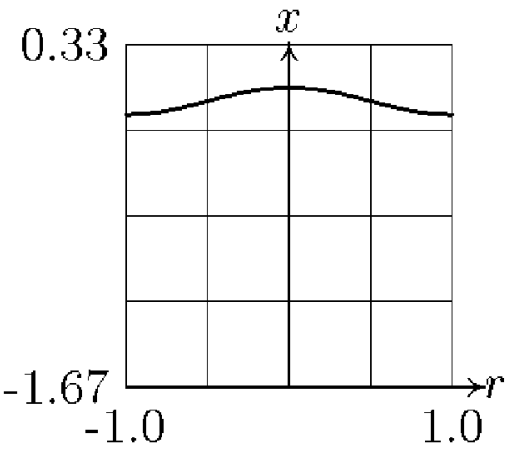

$b$

Fig. 2. Some non-planar CAE shapes (radial cross-section of circular cylinder): $a-\varepsilon=0.0025, k=1.1108 ; \quad a-\varepsilon=0.0025, k=1.3305$;

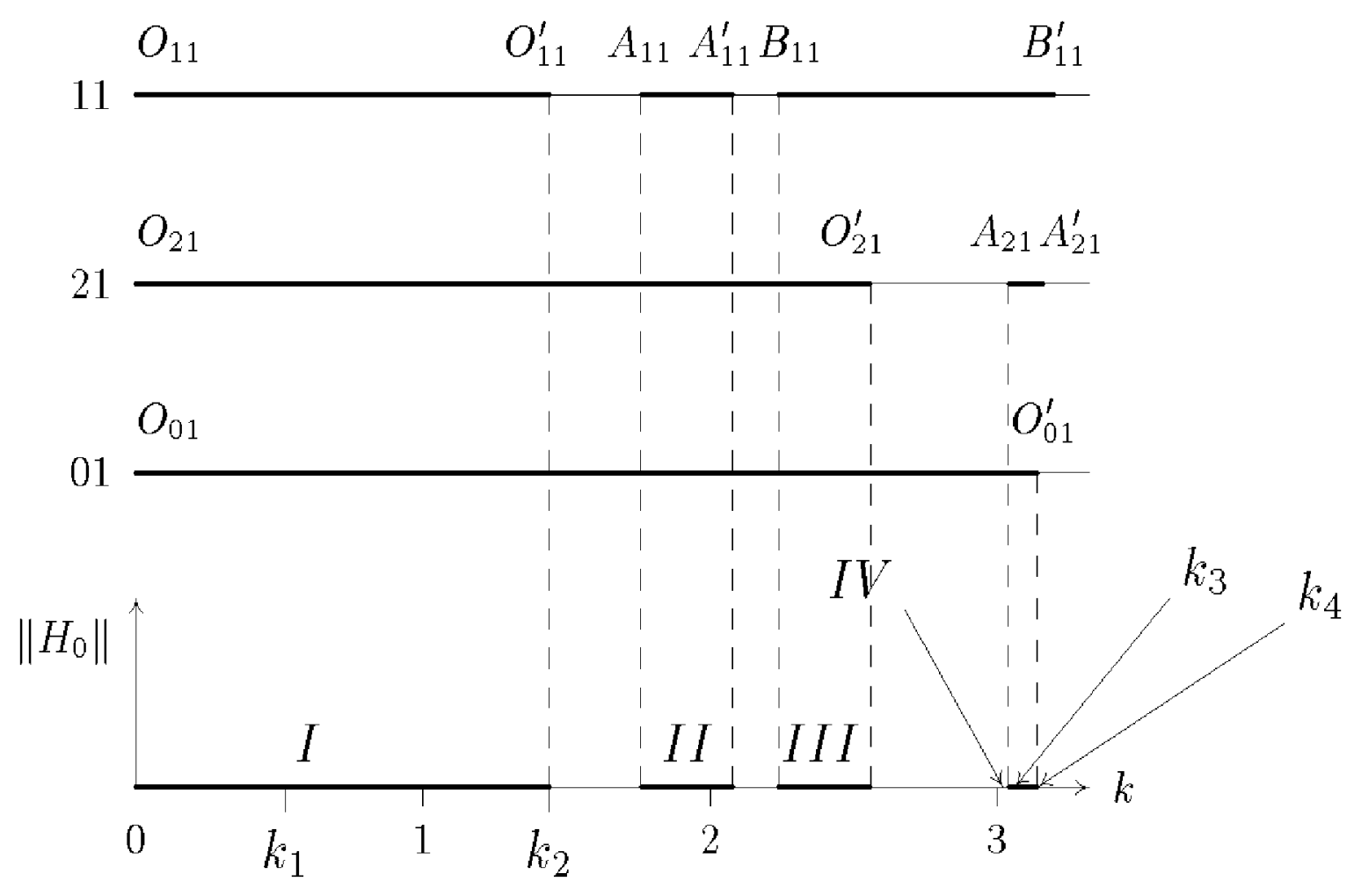

Fig. 3. Stability diagram for positive Bond number 

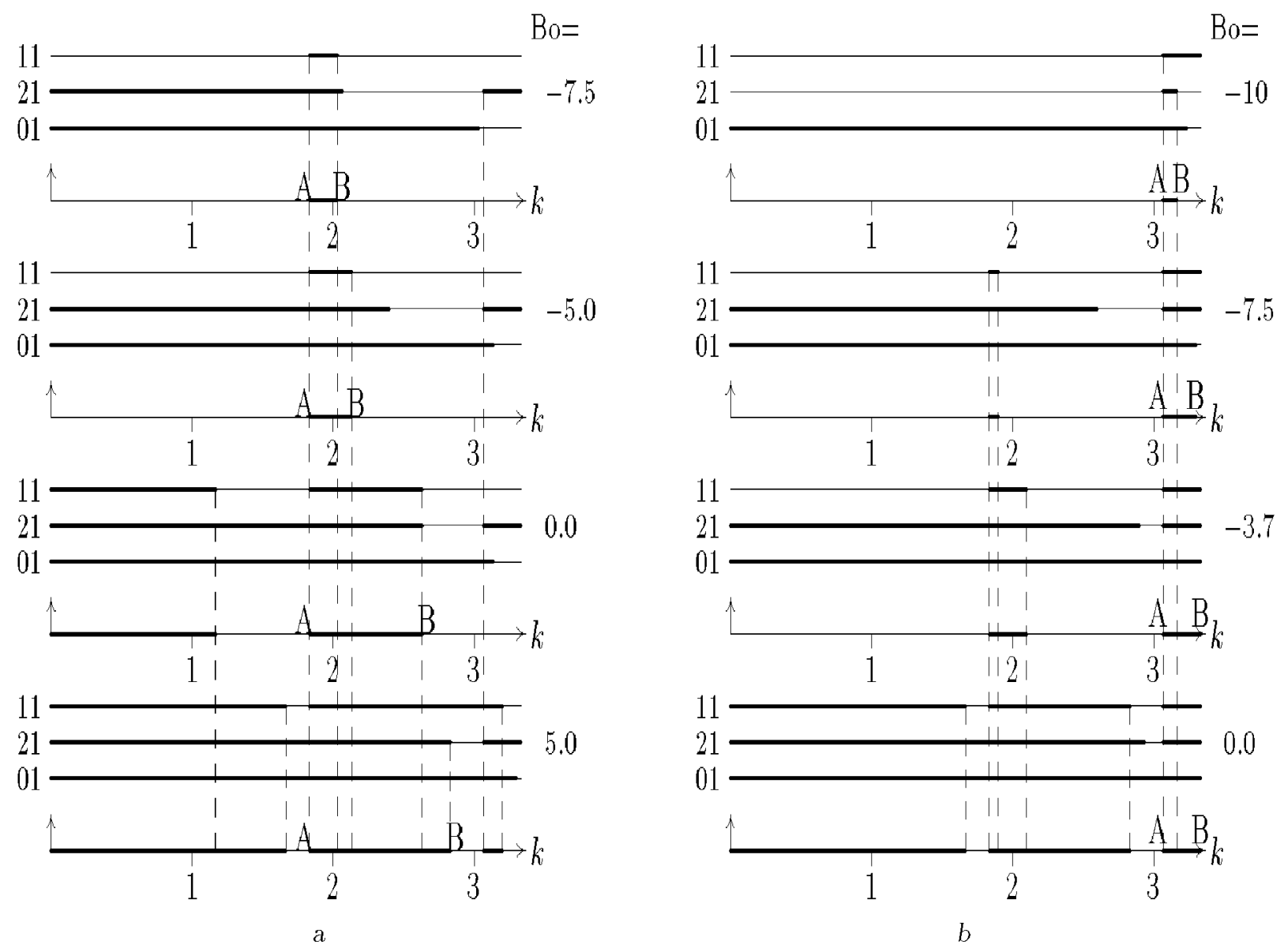

Fig. 4. Stabilization phenomenon: $(A B)$ corresponds to stable planar CAE shape

Analogous phenomenon was found for pendulum on flexible vibrating unit [18].

We can chose $k, \varepsilon$ and $h_{g}$, for which planar CAE shape is stable under negative over-critical Bond number $\left(\mathrm{Bo}+\mathfrak{x}_{11}^{2}<0\right)$. This effect appears to be possible in view to existence of post-resonance ranges of stability $\left(A_{p q}, A_{p q}^{\prime}\right),\left(B_{p q}, B_{p q}^{\prime}\right)$ etc.

First such a situation is shown in fig. 4, a (for $\left.h_{g}=1 ; \varepsilon=0.0035 ; \mathrm{Bo}=-7.5,-5.0\right)$. Here negative Bond numbers $\mathrm{Bo}=-7.5,-5.0$ lead to instability of planar capillary surface due to perturbation by $h_{11}$ $\left(\mathrm{Bo}+\mathfrak{x}_{11}^{2}<0, \mathrm{Bo}+\mathfrak{x}_{p q}^{2}>0, \quad p q \neq 11\right)$. The stability ranges $\left(O_{11}, O_{11}^{\prime}\right)$ are absent for the both examples. The next appropriate range $k \in(A B)$ can be found in the vicinity of the first resonance $k>æ_{11}$. This range of stable planar CAE shape grows only when increasing Bo (see two lower diagrams in fig. 4, a).

The second case is shown in fig. $4, b\left(h_{g}=1.25\right.$; $\varepsilon=0.0025 ; \mathrm{Bo}=-10.5,-7.5,-3.7,0.0 ; \mathrm{Bo}+æ_{11}^{2}<0$, $\left.\mathrm{Bo}+x_{21}^{2}<0, \quad \mathrm{Bo}+x_{p q}^{2}>0, \quad p q \neq 11 ; 21\right)$. Here for $k=-10.0$ planar CAE shape is unstable when per- turbing the modes $h_{11}, h_{21}$. It is necessary to use the second post-resonance range $(A B): k>æ_{21}$ to reach its stabilization. This range $(A B)$ also grows when increasing Bo.

Conclusion 2. A high-frequency acoustic field in gas can stabilize or destabilize "fluid-gas" interface for various Bond numbers. The dynamic stabilization (destabilization) effect is forced by acoustic resonance.

Let us compare the eigenvalues $\lambda_{p q}$ and $\widetilde{\lambda}_{p q}$ for different indexes $p q$. Table gives these values for actual parameters of "water-air" system $(l=0.1 \mathrm{~m}$, $\left.\mathrm{Bo}=0.0, \varepsilon=0.0025, h_{g}=1.25 l, h_{f}=2.0 l\right)$. One can see, that the sound effect on natural frequencies with numbers more than 31 is not principal and the hierarchy

$$
\lambda_{11}^{2}<\lambda_{21}^{2}<\lambda_{01}^{2}<\ldots
$$

holds true for capillary waves. That is why perturbation of natural mode with index 11 (main asymmetric perturbation of interface) is most dangerous. 
Table. Hierarchy of eigenvalues in "water-air" system vs acoustic wavenumber

\begin{tabular}{|c|c|c|c|c|}
\hline Modes & $k=0.0$ & $k=1.48$ & $k=1.85$ & $k=3.7$ \\
\hline$h_{11}$ & 0.4540 & 0.251 & 21.60 & 6.707 \\
$h_{21}$ & 2.075 & 1.963 & 1.882 & 1.588 \\
$h_{01}$ & 4.097 & 3.992 & 3.924 & 1.204 \\
$h_{12}$ & 5.400 & 5.296 & 5.231 & 4.087 \\
$h_{31}$ & 10.95 & 10.85 & 10.79 & 10.11 \\
\hline
\end{tabular}

This hierarchy can hold true for planar stable CAE shape (see $k \in\left(k_{1}, k_{2}\right)$ in fig. 3 or the second column of table). Moreover, for mentioned $k$ the additional inequality $\lambda_{p q}^{2}<\tilde{\lambda}_{p q}^{2}$ holds true. The last means, that the acoustic field can lead to decrease of natural frequencies.

However, the acoustic loading can change the hierarchy (23) (see the last two columns in the table). For $k$ throughout $\left(k_{3}, k_{4}\right)$ (see, fig. 3 ) the symmetric perturbation by mode 01 is most dangerous (because $\left.0<\lambda_{01}^{2}<\lambda_{p q}^{2}, p q \neq 01\right)$. Analogous example is presented in the last column of the table.

Conclusion 3. The effect of acoustic loading of interface can be expressed in essential changes of natural frequencies. It can lead to decrease of the proper frequencies or to increase of frequencies for the selected surface modes. The selected modes can lose stability, although, sometimes, the acoustic field can stabilize a position of balance.

\section{ACOUSTIC PUMPING}

In this section we extend the previous results onto case depicted in fig. 1, c. Vibration of one from the end-walls of the tube creates a standing acoustic wave in gas domain. For the first time the problem was experimentally investigated in [1] where the term "problem on acoustic pumping in microgravity" has been introduced in accordance with possible implementation of acoustic methods for pumping the cryogenic fluid along the tube. This pumping (driven by evaporation phenomenon) is forced by resonance interaction of acoustic field with the interface, so that the resulting force upon the interface exceeds the acoustic radiation pressure [1]. Estimation of pressure shows that phenomenon of acoustic pumping can be explained by intensification of evaporation. The increase of evaporation can be affected only by hydrodynamic instability of sloshing of the interface touching the pulsating gas.

If free surface $\Sigma_{1}$ is stable, the pumping of cryogenic fluid does not occur. In order to describe the acoustic pumping phenomenon we should use a resonance acoustic loading when the sound in $Q_{1}$ desta- bilizes and destroys the interface $\Sigma_{1}$ keeping at the same time the interface $\Sigma_{2}$ stable.

Under the above assumptions we suppose, that $Q$ has the form of circular tube and that the difference of averaged pressures between gas domains $Q_{1}(t)$ and $Q_{3}(t)$ on the interfaces $\Sigma_{1}(t)$ and $\Sigma_{2}(t)$ suppresses the mobility of the mass center of the fluid $Q_{2}(t)$, namely, the small gravity and acoustic radiation pressure do not force it's change. This condition can be easy supplied via relation between the averaged pressure $p_{02}$ in domain $Q_{3}(t)$ and the averaged pressure $p_{01}$ in $Q_{1}(t)$ :

$$
p_{02}=p_{01}-\left(\rho_{02} g h_{f}\right) /\left|S_{0}\right| \text {. }
$$

Here $\left|S_{0}\right|$ is the area of cross-section of cylindrical tube.

We suppose that the sound vibrator is situated on the left hand end-wall $S_{0}$ of $Q$ and pose the origin of coordinate system $O x y z$ on $S_{0}$ tracing $O x$ along the directrix of the cylinder. The vector $\boldsymbol{g}$ (small gravity acceleration) is parallel to $O x$. The coefficient of the surface tension $\sigma$ and contact angle are assumed to be constant.

Let the equation of the interfaces $\Sigma_{i}$ take the form $x=H_{i}(y, z, t)$. When repeating the averaging procedure described above in detail we arrive at the problem on slow-time sloshing:

$$
\begin{aligned}
& \Delta \Phi_{2}=0 \text { in } Q_{2}(\tau) \\
& \frac{\partial \Phi_{2}}{\partial n}=0 \text { on } S_{2} \\
& \frac{\partial \Phi_{2}}{\partial n}=(-1)^{i} \frac{H_{i \tau}}{\left(1+\left(\nabla H_{i}\right)^{2}\right)^{1 / 2}} \text { on } \Sigma_{i}(\tau), \\
& \Phi_{2 \tau}+\frac{1}{2}\left(\nabla \Phi_{2}\right)^{2}+\mu \mu_{1} \times \\
& \times\left(\operatorname{Bo} H_{1}+\operatorname{div} \frac{\nabla H_{1}}{\left(1+\left(\nabla H_{1}\right)^{2}\right)^{1 / 2}}\right)+ \\
& +\frac{1}{4} \mu_{1}\left(k^{2}\left(\Phi_{1}\right)^{2}-\left(\nabla \Phi_{1}\right)^{2}+P\right)=0 \text { on } \Sigma_{1}(\tau), \\
& \varphi_{2 \tau}+\frac{1}{2}\left(\nabla \varphi_{2}\right)^{2}+\mu \mu_{1} \times \\
& \times\left(\operatorname{Bo} H_{1}-\operatorname{div} \frac{\nabla H_{1}}{\left(1+\left(\nabla H_{1}\right)^{2}\right)^{1 / 2}}\right)=0 \text { on } \Sigma_{2}(\tau), \\
& (-1)^{i} \frac{H_{, y} W_{y}+H_{, z} W_{, z}}{|\nabla W|}=\cos \alpha \sqrt{1+\left(\nabla H_{i}\right)^{2}} \text { on } \partial \Sigma_{i}(\tau),
\end{aligned}
$$




$$
\begin{aligned}
& \Delta \Phi_{1}+k^{2} \Phi_{1}=0 \text { in } Q_{1}(\tau), \\
& \frac{\partial \Phi_{1}}{\partial n}=0 \text { on } S_{1} \cup \Sigma_{1}(\tau), \\
& \frac{\partial \Phi_{1}}{\partial x}=\frac{V(y, z)}{k} \text { on } S_{0}, \\
& \left\langle\int_{S_{0}}\left(k^{2}\left(\Phi_{1}\right)^{2}-\left(\nabla \Phi_{1}\right)^{2}+P\right) d s\right\rangle=0,
\end{aligned}
$$

where $P=$ const is chosen from the last integral condition (averaged pressure on $S_{0}$ is constant); $\varepsilon=\sup \left|V_{0}\right| / c$. The case $V \equiv 0$ corresponds to capillary fluid sloshing of a "fluid cork" in micro-gravity.

The problem on CAE for this case is divided into two independent problems for

$$
\Sigma_{01}=\left\langle\Sigma_{1}\right\rangle\left(x=H_{01}(y, z), \Phi_{01}=\Phi_{01}(x, y, z)\right)
$$

and

$$
\Sigma_{02}=\left\langle\Sigma_{2}\right\rangle\left(x=H_{02}(y, x)\right)
$$

namely,

$$
\begin{gathered}
\mu\left(\operatorname{Bo} H_{01}+\operatorname{div} \frac{\nabla H_{01}}{\sqrt{1+\left(\nabla H_{01}\right)^{2}}}\right)+ \\
+\frac{1}{4}\left(k^{2}\left(\Phi_{01}\right)^{2}-\left(\nabla \Phi_{01}\right)^{2}+P\right)=0 \\
\text { on } \Sigma_{01} \\
\Delta \Phi_{01}+k^{2} \Phi_{01}=0 \text { in } Q_{01} \\
\frac{\partial \Phi_{01}}{\partial n}=0 \text { on }\left\langle S_{1}\right\rangle \cup \Sigma_{01} \\
\frac{\partial \Phi_{01}}{\partial n}=\frac{V(y, z)}{k} \text { on } S_{0}
\end{gathered}
$$

and

$$
\begin{gathered}
\mu\left(\operatorname{Bo} H_{02}+\operatorname{div} \frac{\nabla H_{02}}{\sqrt{1+\left(\nabla H_{02}\right)^{2}}}\right)= \\
=-\left(P-\frac{\mu \mathrm{Bo} h_{f}}{\left|S_{0}\right|}\right) \text { on } \Sigma_{02}
\end{gathered}
$$

where

$$
\begin{gathered}
(-1)^{i} \frac{H_{, y} W_{, y}+H_{, z} W_{, z}}{|\nabla W|}=\cos \alpha \sqrt{1+\left(\nabla H_{0 i}\right)^{2}} \\
\text { on } \Sigma_{0 i}, i=1,2 ; \\
\int_{\left\langle Q_{2}\right\rangle} d Q=\text { const. }
\end{gathered}
$$

In order to investigate the stability of $\Sigma_{01}$ and $\Sigma_{02}$ we use "the static spectral criteria":

- CAE shape (surface $\Sigma_{01}\left(x=H_{01}(y, z)\right)$ plus surface $\left.\Sigma_{02}\left(x=H_{02}(y, z)\right)\right)$ is stable if and only if all eigenvalues $\eta_{l}^{(1)}$ and $\eta_{l}^{(2)}$ determined from the spectral problems

$$
-\eta^{(1)} h+\mathcal{A}^{1} h=0 \text { on } \Sigma_{01}
$$

$$
\begin{aligned}
\mathcal{A}^{1} h=\operatorname{Bo} h+\operatorname{div} & {\left[\frac{\nabla h}{\sqrt{1+\left(\nabla H_{01}\right)^{2}}}-\right.} \\
& \left.-\frac{\left(\nabla h, \nabla H_{01}\right) \nabla H_{01}}{\left(1+\left(\nabla H_{01}\right)^{2}\right)^{3 / 2}}\right]+
\end{aligned}
$$$$
+\frac{2}{\mu}\left[k^{2} \Phi_{01} \Phi_{01, x} h-\left(\nabla \Phi_{01}, \nabla \Phi_{01, x}\right) h+\right.
$$

$$
\left.+k^{2} \Phi_{01} \Phi-\left(\nabla \Phi_{01}, \nabla \Phi\right)\right]_{\Sigma_{01}} \text { on } \Sigma_{01},
$$

$$
\begin{aligned}
& -\frac{\left(h_{, y} W_{, y}+h_{, z} W_{, z}\right)}{\left(H_{0, y} W_{, y}+H_{0, z} W_{, z}\right)}= \\
& =\frac{\left(\nabla H_{0}, \nabla h\right)}{\left.{\sqrt{1+\left(\nabla H_{01}\right.}}^{2}\right)} \text { on } \partial \Sigma_{01},
\end{aligned}
$$

$\int_{\Sigma_{01}} h d y d z=0$

$$
\Delta \Phi+k^{2} \Phi=0 \quad \text { in } Q_{01}
$$$$
\frac{\partial \Phi}{\partial n}=0 \quad \text { on }\left\langle S_{1}\right\rangle \cup S_{0}
$$$$
\frac{\partial \Phi}{\partial n}=-\left\{\Phi_{01, x x} h-\Phi_{01, z} h_{, z}-\Phi_{01, y} h_{, y}-\right.
$$

$$
\begin{aligned}
& \left.-\left[\Phi_{01, x y} H_{0, y}+\Phi_{01, x z} H_{0, z}\right] h\right\} \times \\
& \times 1 / \sqrt{1+\left(\nabla H_{0}\right)^{2}} \text { on } \Sigma_{01}
\end{aligned}
$$

(here $\Phi_{01}$ is the solution of the problem (26); $\Phi(x, y, z)$ describes changing of wave function in $Q_{01}$ due to perturbation of free interface 
$\left.\Sigma_{01}: x=h_{1}(y, z)\right)$ and from the spectral problem

$$
\begin{gathered}
-\eta^{(2)} h+\mathcal{A}^{2} h=0 \text { on } \Sigma_{02}, \\
\mathcal{A}^{2} h=\operatorname{Bo} h-\operatorname{div}\left[\frac{\nabla h}{\sqrt{1+\left(\nabla H_{02}\right)^{2}}}-\right. \\
\left.-\frac{\left(\nabla h, \nabla H_{02}\right) \nabla H_{02}}{\left(1+\left(\nabla H_{02}\right)^{2}\right)^{3 / 2}}\right] \text { on } \Sigma_{02},
\end{gathered}
$$$$
\frac{h_{, y} W_{, y}+h_{, z} W_{, z}}{H_{0, y} W_{, y}+H_{0, z} W_{, z}}=
$$$$
=\frac{\left(\nabla H_{0}, \nabla h\right)}{\sqrt{1+\left(\nabla H_{02}\right)^{2}}} \text { on } \partial \Sigma_{02}
$$$$
\int_{\Sigma_{02}} h d y d z=0
$$

are positive ones $\left(\eta_{l}^{(i)}>0, i=1,2\right)$. Negative $\eta_{l}^{(1)}$ corresponds to unstable $\Sigma_{01}$ and negative $\eta_{l}^{(2)}$ corresponds to unstable $\Sigma_{02}$.

\section{PLANAR CAE SHAPES AND INSTABILITY OF "FLUID CORK"}

The simplest way to show the effect of acoustic field is to consider the system when $\alpha=\pi / 2, V=1$. In this case the surfaces $\Sigma_{01}$ and $\Sigma_{02}$ (both in the presence of planar acoustic field $V=1$ and sound free case) are planar ones, i.e.,

$$
\begin{gathered}
H_{01}(y, z)=h_{g}, \quad H_{02}(y, z)=h_{g}+h_{f}, \\
\Phi_{01}(x, y, z)=\frac{\cos \left(k\left(x-h_{g}\right)\right)}{k^{2} \mu_{0}} .
\end{gathered}
$$

Here $\mu_{0}=\sin \left(k h_{g}\right)$.

The problems (29) and (31) are solved by method of separation of spatial variables in cylindrical coordinate system. The natural modes on the free surfaces $\Sigma_{01}$ and $\Sigma_{02}$ are

$$
h_{i}^{(p q)}=\left(J_{p}\left(æ_{p q} r\right) \begin{array}{l}
\sin \\
\cos
\end{array}(p \theta)\right), \quad J_{p}^{\prime}\left(æ_{p q}\right)=0 .
$$

The eigenvalues are

$$
\begin{aligned}
\eta_{p q}^{(1)}= & \mu \mu_{1}\left(æ_{p q}^{2}-\mathrm{Bo}\right)- \\
& -\frac{1}{2}\left\{\begin{aligned}
1 /\left(\eta \operatorname{th}\left(\eta h_{1}\right)\right), & k^{2}<æ_{p q}^{2}, \\
-1 /\left(\eta \operatorname{tg}\left(\eta h_{1}\right)\right), & k^{2} \geq æ_{p q}^{2},
\end{aligned}\right. \\
\eta_{p q}^{(2)}= & \mu \mu_{1}\left(æ_{p q}^{2}+\mathrm{Bo}\right),
\end{aligned}
$$

where $\eta=\sqrt{\left|k^{2}-x_{p q}^{2}\right|}$. Note, that for capillary surface natural modes are the same ones, but

$$
\begin{aligned}
& \tilde{\eta}_{p q}^{(1)}=\mu \mu_{1}\left(æ_{p q}^{2}-\mathrm{Bo}\right) ; \\
& \tilde{\eta}_{p q}^{(2)}=\mu \mu_{1}\left(æ_{p q}^{2}+\mathrm{Bo}\right) .
\end{aligned}
$$

Capillary planar surface is stable if and only if $-æ_{11}<$ Bo $<æ_{11}$. However, in accordance with (32), there exists such a wave number $k$, that $\eta_{p q}^{(1)}<0$ for any Bond number, even for $B o=0$. This means that the surface $\Sigma_{01}$ can become unstable due to acoustic loading. When analyzing the expression for $\eta_{11}^{(1)}$ in details we find out that for any Bond number planar $\Sigma_{01}$ is not stable as $k \rightarrow æ_{11}$ - (the frequency of sound is close to the first natural tone of acoustic field in gas), because $\eta_{11}^{(1)}$ tends to $-\infty$ as $k \rightarrow æ_{11}$. Just such a resonance phenomenon was observed in the experimental work [1].

Conclusion 4. The acoustic pumping of a cryogenic fluid in zero-gravity utilizes the hydrodynamic instability phenomenon forced by acoustic resonance.

\section{CONCLUSIONS}

A number of analytical and numerical solutions of averaged problems on CAE and the slow-time sloshing of "fluid-gas" interface under zero-gravity conditions exposed to acoustic vibrations of gas domain confirms the good agreement of the theory with experimental data. The examples concern the case of cylindrical vessel with low-gravity acceleration vector along the directrix. This limitation makes available the comparison with trivial (planar) solutions of capillary problem.

We show that if the sound vibrator modulates a non-planar acoustic field then CAE shape is not planar one even for positive Bond number. This means that CAE shape does not coincide with capillary shape. However, even if the acoustic vibrator produces planar acoustic field in gas and CAE shape is also planar one, no conclusion about the stability of this interface can be made. Acoustic loads change drastically the dynamic properties of the sloshing interface, so the analysis of new stability is necessary. We propose a simple analytical way how to find the range of exciting frequencies, for which the planar equilibrium shape is unstable in contrast to the planar capillary surface. It is transparent treatment of the destabilization phenomenon. On the other hand, we have found out the stabilization phenomenon, namely, we calculated the ranges of exciting frequencies, for which the planar CAE shape is stable when capillary planar surface is unstable. The both ranges 
are situated near a natural frequency of acoustic vibration of gas domain. In addition, the acoustic loads always lead to the drift of spectrum of the problem on natural vibration with respect to CAE. It is expressed through the decrease of natural tones or to their increase for selected surface modes.

We implement the same technique to analyze the acoustic pumping phenomenon ("fluid cork" movement in a tube supplied by acoustic action upon one from interfaces). When utilizing the resonant excitation we have found the range of frequencies, at which the interface interacting with the acoustic field is unstable for arbitrary Bond number.

\section{ACKNOWLEDGEMENT}

Authors are grateful for support in part made by Deutsche Forschungsgemeinschaft.

1. Wesseln Ph. S. Acoustic pumping in cryogenic liquid // Design. News.- 1967.- 22, N 12.- P. 96-102.

2. Корнфельд М., Молохова Н. Вспучивание поверхности жидкости под воздействием ультразвука //
Докл. АН СССР.- 1955.- 105, N 3.- С. 476-477.

3. Ingard U., Ross J. A. Jr. Some aspects of the interaction of sound with a liquid surface // Proc. 7-th Int. Congr. Acoust. Vol. 2.- Budapest, 1971.- P. 213-216.

4. Wolf G. H. Dynamic stabilization of the interchange instability of a liquid - gas Interface // Phys. Rev. Let.- 1970.- 24, N 9.- P. 444-446.

5. Ганиев Р. Ф., Лакиза В. Д., Дапенко А. С. О динамическом поведении свободной поверхности жидкости в условиях, близких к невесомости, при вибрашионном воздействии // Прикл. мех.- 1977.13. N 5.- C. $102-107$.

6. Любимов Д. В., Черепанов А. А. О возникновении сташионарного рельефа на поверхности раздела жидкостей в вибрашионном поле // Изв. АН СССР. Механика жидкости и газа.- 1986.- N 6.- С. 8-13.

7. Tian Y., Holt R. G., Apfel R. E. Deformation and location of an acoustically levitated liquid drop // J. Acoust. Soc. Amer.- 1995.- 93.- P. 3096-3104.

8. Lee C. P., Anilkumar A. V., Wang T. G. Static shape of an acoustically levitated drop with wave-,drop interaction // Phys. Fluids.- 1994.- 6, N 11.- P. 35543566.

9. Principal investigator: T. Wang / Drop physics module / Drop dynamics experiment // The second United States Microgravity Laboratory (USML-2). 90-day Science Report.- March, 1996.- P. 69-71.

10. Apfel R. E., Tian Y., Jankovsky J., Shi T., Chen X., Holt R. G., Trinh E., Croonguist A., Thornton K. C., Sacco A. Jr., Colemen C., Leslie F. W., Matthiesen D. H. Free oscillations and surfactant stu- dies of superdeformed drops in microgravity // Phys. Rev. Let.- 1998.- 78, N 10.- P. 1912-1915.

11. Lee C. P., Anilkumar A. V., Hmelo A. B., Wang T. G. Equilibrium of liquid drops under effects of rotation and acoustic flattening: Results from USML-2 experiments in space // J. Fluid Mech.- 1998.- 354.P. 43-67.

12. Tao Shi, Apfel R. Instability of an interface between two fluids in an acoustic field // ASA 127-th Meeting M.I.T.- 1994, June, 6-10.- P. 1-2.

13. Lukovsky I. A., Timokha A. N. One class of boundary value problems of the theory of surface waves // Ukr. Math. J.- 1991.- 43, N 3.- P. 359-364.

14. Faltinsen $O$. M. A nonlinear theory of sloshing in rectangular tanks // J. Ship Res.- 1974.- 18, N 4.P. 224-241.

15. Луковский И. А. Введение в нелинейную динамику твердых тел с полостями, частично заполненными жидкостью.- K.: Наук. думка, 1990.- 296 с.

16. Myshkis A. D. Babsky V. G., Kopachevskii N. D., Slobozhanin L. A., Typsov A. D. Low-gravity fluid mechanics. Mathematical theory of capillary phenomena.- Berlin etc: Springer, 1987.$\mathrm{XIX}+583 \mathrm{p}$.

17. Капица П. Л. Маятник с вибрируюшим подвесом // Успехи физических наук.- 1951.- 44, вып. 1.- С. 34-42.

18. Новиков Л. 3., Харламов С. А. Об особенностях поведения маятника с упругим подвесом на вибрируюшем основании // Изв. АН СССР. Механика твердого тела.- 1973.- N 5.- C. 3-13.

19. Capodanno P. Sur l'existence des petities oscillations d'une colonal liquide cylindrique en apesanteur // ZAMP.- 1994.- 45.- P. 81-98.

20. Concus P. Finn R. Capillary wedges revisited // SIAM J. Math. Anal.- 1996.- 27, N 1.- P. 56-69.

21. Finn R., Marek J. The modified canonical proboscis // Z. Anal. Anwend.- 1996.- 15 N 1.- P. 95108.

22. Finn $R$. On the contact angle in capillarity // Proc. 3rd Int. Colloquium on Differential Equations.- Plovdiv, Bulgaria, August 18-22, 1992.- P. 55-62.

23. Concus P., Finn R., Weislogel M. Drop-tower experiments for capillary surfaces in an exotic container // AIAA J.- 1992.- 30, N 1.- P. 134-137.

24. Beyer K., Gawriljuk I. P., Guenther M., Lukovsky I., Timokha A. Compressible potential flows with free boundaries. Part I: Vibrocapillary equilibria // Universitaet Leipzig. Preprint NTZ.-N 1, 1999.- P. 1-18.

25. Луковский И. А., Тимоха А. Н. О свободных колебаниях системы “жидкость - газ" в цилиндрическом сосуде в слабом гравитационном поле // Прямые методы в задачах динамики и устойчивости многомерных систем.- K.. Институт математики AH YCCP, 1986.- C. 5-12.

26. Уральцева H. Н. Разрешимость задачи о капилляpax // Вестн. Ленигр. ун-та.- 1975.- 1, вып. 1.C. 143-149. 